\title{
Prevalence and Predictors of Fruit Intake Among Community College Women in the Extended Opportunity Program and Services
}

\author{
Steven E. Shive and Michelle R. Neyman \\ California State University, Chico
}

\begin{abstract}
This study examined fruit intake among 276 female Extended Opportunity Program and Services (EOPS) community college students. Knowledge, attitudes, and behaviors associated with fruit intake were determined. The attitudes which are potential predictors of daily fruit intake were also examined. Analysis showed that 33\% ate fewer than the minimum recommended two daily servings of fruit. Students reported that fruit gave them energy, taste and cost were not barriers to consumption and that it would not be difficult to increase daily fruit consumption. A linear regression analysis revealed that beliefs that eating fruit leads to good health, having a habit of eating fruit, feeling energy, and weight loss accounted for $30 \%$ of the variance in fruit intake.
\end{abstract}

(C) 2003 Californian Journal of Health Promotion. All rights reserved.

Keywords: diet, fruit, community colleges, women

\section{Introduction}

Diet related diseases, such as heart disease, cancer, and stroke, have consistently been among the top three leading causes of death (California Cancer Facts and Figures, 2001). A recent analysis of cancer causes reported that over $40 \%$ of deaths are associated with the typical American diet (The Harvard Report on Cancer Prevention, 1996). The Framingham Study found that higher fruit and vegetable intake reduced the risk of heart attack and stroke by $20-30 \%$ (Gillman, et al., 1995). Dietary changes, such as eating 5 servings of fruits and vegetables a day, were found to be associated with a reduction in the risk of developing a dozen different cancers by half, as compared to consuming 2 or fewer servings (Block, Patterson $\&$ Subar, 1992). Cancer authorities recommend eating a plant-based diet (American Cancer Society 1996 Advisory Committee on Diet, 1996). Implementation of this recommendation would have a significant impact on health. Even in agricultural areas such as California that have a high availability of fresh produce, fruit and vegetable consumption was below current recommendations suggested by the Dietary
Guidelines for Americans (DiSogra, Abrams \& Hudes, 1994).

Much progress needs to be made given that in 1997 only one in three California adults reported eating 5 servings of fruits and vegetables a day, the minimum recommended for good health. One-third of adults reported they had eaten only 2 or fewer servings, an amount that is associated with higher disease risk (California Department of Health Services CPaNA., 1999). Research on nutrition interventions aimed at improving dietary habits have found that health beliefs, specific food choice knowledge, and being ready to change were positive predictors of healthy eating (California Department of Health Services CPaNA., 1999). Messages geared towards motivations and barriers in addition to health, including taste, cost, convenience, and having more energy, were recommended as likely to support behavior change. It is unclear though whether these dietary habits and attitudes that serve as predictors of healthy eating apply to the EOPS population of women.

While low quality diets are not restricted to individuals with low socioeconomic status, ethnic minority and low-income populations 
may be at increased risk for chronic health problems related to poor nutrition (California Department of Health Services CPaNA., 1999; USDA Agricultural Research Service, 1997).

Teenagers, women following popular weight loss diets and college students may be at risk for inadequate nutrient intakes regardless of economic status. College students are at a time and place in life where their behavior is very conducive to change; in fact, the student's social role of learner is largely defined by a readiness to change (The National Health, 1998).

California Project LEAN (Leaders Encouraging Activity and Nutrition), a program of the California Department of Health Services, aims to increase the accessibility of healthy foods and physical activity options in communities by working with 10 regional networks, industry, voluntary organizations and the media. Project LEAN sponsors programs which motivate at risk (i.e. ethnic minority, low income) students to make healthier food and exercise choices, supports school cafeterias to promote low-fat menu items, advocates for healthier food choices on campuses, and provides a model which can be replicated (Health and Education Communication Consultants, 1996). Given the relationship of diet to overall health and well being, Project LEAN staff identified female community college students in the Extended Opportunity Program and Services (EOPS) as an at risk group and fruit intake as the primary health behavior to address. EOPS is a student support program for educationally and economically disadvantaged students, designed to provide higher education opportunities for those with academic potential who, historically, would not have attended college (California Project LEAN, 2000). Poverty places individuals at risk for nutrition problems and one of the goals of Healthy People 2010 is the reduction in health disparities between segments of the population (Hall \& Richards, 1995; U.S. Department of Health and Human Services, 2000). A review of literature shows no intervention studies having been conducted at community colleges, especially among at risk populations.
The purpose of this study was to conduct an assessment of the knowledge, attitudes, and dietary intake of fruit among female EOPS students and to determine the attitudes that are potential predictors of fruit intake among this population. This information could be incorporated into the development of materials to be used in an intervention specifically aimed at increasing fruit consumption among EOPS community college students. An accurate assessment is essential in order to set priorities and form the basis for an action plan to accomplish these long-term goals (Kubik, Lytle \& Story, 2001).

\section{Methods}

\section{Sample Population}

The sample consisted of 276 women in the EOPS programs at two community colleges in Northern California in the Spring 2001 semester. EOPS women were selected for several reasons. EOPS exists at all community colleges and can provide access to low income women. In addition, community colleges collect accurate documentation on income, have historically provided outreach into low income communities, comprise a network for outreach in future years, and EOPS draws in a significant number of ethnic groups. EOPS women are a special needs population because they have unique educational needs due to language, social, and economic barriers that put them at risk for poor nutrition (Hall \& Richards, 1995). The community colleges that were selected were in the Sierra Cascade Project LEAN Region.

Sample size was determined to provide adequate power in testing for linear regression analysis. The Human Subjects Review Committee at California State University, Chico approved all procedures and consent was given on the survey form.

\section{Data Collection and Measurement}

A cross-sectional, quasi-experimental design was used in this study. A survey was developed to measure knowledge, attitudes, and behavior of fruit intake. Staff in the EOPS programs conducted the voluntary survey by distributing it at the beginning of the semester with other EOPS materials or by mail. Monetary incentive (\$100 raffle) was provided for participation in 
completion of the questionnaire that took approximately 10 minutes. Overall, 276 students participated. This response represented a $45.8 \%$ return rate for those surveyed.

\section{Instrument}

The 42-item questionnaire was composed of five sections and included items about daily fruit intake, knowledge, attitudes, food consumption practices, and demographics. Daily fruit intake was assessed with four items which asked respondents to check whether they consumed any fruit or $100 \%$ fruit juice for breakfast, lunch, dinner, and snacks the previous day and if so, how many servings. A serving size was defined on the questionnaire as being equivalent to one whole piece of fruit, or $3 / 4$ cup $100 \%$ fruit juice, or $1 / 2$ cup canned fruit or $1 / 4$ cup dried fruit. Responses ranged from none or less than one, to five or more.

Knowledge was assessed by an item that asked respondents if they thought eating "fruit reduced the risk of getting the following cancers" and respondents responded (yes/no) to a list of cancers that were provided. Participants were also asked if they could name any foods that reduced the risk of getting cancer and heart disease. Attitudes (based on a on a 4-point Likert scale, where $1=$ strongly disagree and $4=$ strongly agree) were assessed and included whether participants felt more energy when they ate fruit, provided an example for their family, found it difficult to obtain at work or when dining out, cost, length of preparation time, health benefits, perceived taste, habit of eating fruit, assist in weight loss, reduce cancer risk, ate enough for good health, perceived taste, and whether or not it spoiled easily. Demographics included sex, age, country of birth, length of time in the U.S., marital status, children living at home, employment status, and perceived norms of fruit consumption.

The following items were modified from existing questionnaires: daily fruit intake, and attitudes regarding feeling energy, weight loss, difficulty in obtaining fruit, cost, spoilage, difficulty in preparation, and taste (California Department of Health Services CPaNA., 1999). Items assessing the difficulty in obtaining one additional serving of fruit, foods related to cancer and disease reduction, attitudes regarding difficulty in obtaining fruit in fast food restaurants, setting an example and health benefits to family, and relationship of cancer to lifestyle were developed for this study.

Reliability in the present study was estimated by the test-retest method in a pilot study of the questionnaire using students who did not participate in the present study. A total of 58 female students participated in the first administration, and of these, 54 participated in the second administration that occurred at a two week interval. Analysis of the consistency in test-retest responses included the use of kappa statistics (dichotomous variables), unweighted kappa statistics (polychotomous variables), and the Pearson correlation coefficients (for continuous variables) (Fleiss, 1981; SPSS, 1999).

SPSS version 10.0 was used in the descriptive statistics and linear regression analysis. Descriptive statistics were conducted for the demographic variables, estimated amount of fruit intake, perceived peer intake, attitudes toward fruit intake, and knowledge of fruit intake and reduced risk of cancer. Linear regression analysis was used in the present study to identify potential predictor variables of fruit intake. The independent variables included: the belief that they felt more energy when they ate fruit, provided an example for their family, found it difficult to obtain at work or when dining out, cost, length of preparation time, health benefits, perceived taste, habit of eating fruit, assist in weight loss, reduce cancer risk, ate enough for good health, perceived taste, whether or not it spoiled easily and experts recommend two or more servings a day. The dependent variable was amount of daily fruit intake. A forward selection of variables was used to select variables for inclusion in the final model. The criterion for entry of variables was .05 for each step and the significance criterion for selection of whether the variable remained was .10 (SPSS, 1999). 


\section{Results}

\section{Demographics}

The mean age of the 276 respondents was 30.1 years, with the majority of students being between 19-40 years of age (Table 1). The majority of the sample was White $(74.9 \%)$ followed by Hispanics (9.8\%), Blacks (4.4\%), and Asians (4.0\%). Thirty-nine percent of the sample reported never having been married, $20 \%$ were divorced, and $26 \%$ were currently married, and $15 \%$ were separated or widowed. Of the total sample, $51 \%$ were unemployed and $27 \%$ reported annual incomes of less than $\$ 3,000$.

Table 1

Demographic Characteristics of Female EOPS Students by Percentage

\begin{tabular}{|c|c|}
\hline Demographics & $\begin{array}{c}(\%) \\
N=276\end{array}$ \\
\hline \multicolumn{2}{|l|}{ Race/Ethnicity } \\
\hline Asian/Pacific Islander & 4.0 \\
\hline Black & 4.4 \\
\hline Hispanic & 9.8 \\
\hline American Indian & 2.9 \\
\hline White & 74.9 \\
\hline Other & 4.0 \\
\hline \multicolumn{2}{|l|}{$\operatorname{Age}^{\mathrm{a}}$} \\
\hline $16-18$ & 5.1 \\
\hline $19-22$ & 27.5 \\
\hline $23-30$ & 27.1 \\
\hline $31-40$ & 24.2 \\
\hline $41-50$ & 11.7 \\
\hline $51-60$ & 3.3 \\
\hline $61+$ & 1.1 \\
\hline \multicolumn{2}{|l|}{ Marital Status } \\
\hline Married & 27.0 \\
\hline Unmarried & 32.7 \\
\hline Never Married & 40.3 \\
\hline Have children $<18$ at home & 61.6 \\
\hline \multicolumn{2}{|l|}{ Employment Status } \\
\hline Full Time & 13.1 \\
\hline Part Time & 36.0 \\
\hline Unemployed & 50.9 \\
\hline \multicolumn{2}{|l|}{ Income Level } \\
\hline$<\$ 3,000$ & 27.0 \\
\hline$\$ 3,001-6,000$ & 17.3 \\
\hline$\$ 6,001-9,000$ & 19.8 \\
\hline$\$ 9,001-12,000$ & 14.1 \\
\hline$\$ 12,001-15,000$ & 8.9 \\
\hline$\$ 15,001-18,000$ & 4.8 \\
\hline$>\$ 18,000$ & 8.1 \\
\hline \multicolumn{2}{|c|}{$\begin{array}{l}\text { Note. EOPS = Extended Opportunities Program and } \\
\text { Services } \\
{ }^{a} \text { Mean age }(\mathrm{SD})=30.1(10.7)\end{array}$} \\
\hline
\end{tabular}




\section{Reliability of the Questionnaire}

Differences across administrations for demographic characteristics were small and nonsignificant, indicating excellent ( 0.75 or greater) or fair to good (0.40 to 0.75 ) agreement (Table 2). Perceptions of the difficulty of obtaining one additional serving of fruit had good agreement (0.63), and perceptions of the norms among peers had poor agreement $(0.34)$. The items that measured key attitudes in regard to physiological effects and barriers to fruit intake all had good agreement, ranging from 0.59-0.73 (Table 2). Eating fruit to set a good example for the family had poor agreement (0.28). Knowledge of the recommended minimum intake of fruit (0.23) and knowledge that fruit intake reduced cancer risk (0.29) had poor agreement. Overall, the questionnaire items had acceptable levels of reliability. The items that had poor agreement were modified to improve the clarity of the question. They were not discarded because they were standard questions used in nutrition assessments, may have measured real change over time, or may be an effect from test taking.

Table 2

Consistency Across Two Administrations of the EOPS Fruit Intake Survey

\begin{tabular}{|c|c|}
\hline & $\begin{array}{c}\text { Test-retest reliability } \\
(\mathrm{N}=54)\end{array}$ \\
\hline \multicolumn{2}{|l|}{ Demographics } \\
\hline Sex: & 1.00 \\
\hline Race: & 1.00 \\
\hline Age: mean years $(\mathrm{SD})^{\mathrm{a}}$ & 1.00 \\
\hline Marital Status & 0.88 \\
\hline Income Level & 0.68 \\
\hline Children less than 18 years of age & 1.00 \\
\hline \multicolumn{2}{|l|}{ Perceptions } \\
\hline Perceived percentage of peers who eat 1 serving daily & 0.34 \\
\hline Perceived difficulty in obtaining 1 additional serving & 0.63 \\
\hline \multicolumn{2}{|l|}{ Attitudes $^{\mathrm{a}}$} \\
\hline Feel more energy when eat fruit & 0.68 \\
\hline Eating fruit sets an example for my family & 0.28 \\
\hline Fruit spoils & 0.68 \\
\hline Cost of fruit is too expensive & 0.73 \\
\hline Personally do not like the taste of fruit & 0.59 \\
\hline \multicolumn{2}{|l|}{ Knowledge $^{\mathrm{a}}$} \\
\hline Health experts recommend 2 servings/day & 0.23 \\
\hline Cancer risk reduced by fruit intake & 0.09 \\
\hline \multicolumn{2}{|c|}{$\begin{array}{l}\text { Note. The test-retest reliability is measured by kappa statistics for all dichotomous and polychotomous } \\
\text { variables. }\end{array}$} \\
\hline \multicolumn{2}{|c|}{$\begin{array}{l}\text { a The test-retest reliability is measured by Pearson's correlation coefficients for these continuous } \\
\text { variables. }\end{array}$} \\
\hline
\end{tabular}




\section{Fruit Intake}

Overall, $44.7 \%$ of women reported having at least some fruit for breakfast, $43.1 \%$ for lunch, and $40.6 \%$ for dinner (Table 3). Of the total sample, $32.8 \%$ consumed fewer than the recommended minimum two servings of fruit over the course of the previous day. Among those reporting fruit consumption at breakfast the previous day, $59.4 \%$ ate one serving or less, while at lunch and dinner the proportion consuming that amount was $75.1 \%$ and $66.7 \%$, respectively. Among the EOPS women, $79.5 \%$ reported eating one serving or less of fruit at inbetween meal snacks the previous day. Women $(45.6 \%)$ reported that they thought that less than $40 \%$ of their peers had at least one serving of fruit per day.

Table 3

Fruit Intake and Perceived Norms by Percent

\begin{tabular}{|c|c|}
\hline & $\%$ \\
\hline Fruit Intake at Meals & $\mathrm{N}=276$ \\
\hline Breakfast & 44.7 \\
\hline Lunch & 43.1 \\
\hline Dinner & 40.6 \\
\hline Amount of Fruit Intake at meals & $\mathrm{N}=175$ \\
\hline \multicolumn{2}{|l|}{ Breakfast } \\
\hline$\leq 1$ serving & 59.4 \\
\hline 2 servings & 26.9 \\
\hline$\geq 3$ servings & 13.7 \\
\hline \multicolumn{2}{|l|}{ Lunch } \\
\hline$\leq 1$ serving & 75.1 \\
\hline 2 servings & 17.8 \\
\hline$\geq 3$ servings & 7.1 \\
\hline \multicolumn{2}{|l|}{ Dinner } \\
\hline$\leq 1$ serving & 66.7 \\
\hline 2 servings & 23.4 \\
\hline$\geq 3$ servings & 9.9 \\
\hline Snack & $\mathrm{N}=276$ \\
\hline$\leq 1$ serving & 79.5 \\
\hline 2 servings & 15.0 \\
\hline$\geq 3$ servings & 5.6 \\
\hline \multicolumn{2}{|l|}{ Daily Fruit Servings } \\
\hline$\leq 1$ serving & 32.8 \\
\hline 2 servings & 17.0 \\
\hline$\geq 3$ servings & 50.2 \\
\hline \multicolumn{2}{|l|}{ Perceived percentage of peers who eat one serving of fruit daily } \\
\hline $0-20 \%$ & 13.5 \\
\hline $21-40 \%$ & 32.1 \\
\hline $41-60 \%$ & 36.5 \\
\hline $61-80 \%$ & 14.6 \\
\hline $81-100 \%$ & 3.3 \\
\hline
\end{tabular}




\section{Attitudes Toward Fruit Intake}

As seen in Table 4, overall, in measures of lifestyle attitudes, students agreed that fruit consumption made them feel more energetic (M $=3.04, \mathrm{SD}=.71)$, and would help with weight loss $(\mathrm{M}=3.10, \mathrm{SD}=.80)$. Students agreed that their health benefited $(\mathrm{M}=3.53, \mathrm{SD}=.64)$ their family. The means for not being in the habit of eating fruit, eating enough fruit for good health, and eating fruit to set a good example for their family, ranged from 2.33 to 2.72 .

Table 4

Attitudes Toward Fruit Intake Among EOPS Women (N=276).

\begin{tabular}{|l|c|c|}
\hline \multicolumn{1}{|c|}{ Attitudes } & Mean(SD) & 95\% C.I. \\
\hline Feel more energy when eat fruit & $3.04(.71)$ & $-.33,-.001$ \\
\hline Fruit would help with weight loss & $3.10(.80)$ & $-.14, .25$ \\
\hline Fruit will reduce risk of cancer & $3.29(.69)$ & $-.32, .01$ \\
\hline Not in habit of eating fruits & $2.33(.94)$ & $-.41, .05$ \\
\hline Eat enough fruit for good health & $2.44(.91)$ & $-.36, .08$ \\
\hline Food intake related to cancer & $2.79(.88)$ & $-.34, .09$ \\
\hline Eating fruit sets an example for my family & $2.72(.87)$ & $-.16, .15$ \\
\hline My health benefits my family & $3.53(.64)$ & $-.08, .33$ \\
\hline Spoils & $2.62(.78)$ & $-.35, .21$ \\
\hline Difficulty obtaining at work & $2.45(.97)$ & $-.30, .16$ \\
\hline Difficulty obtaining while dining out & $2.64(1.01)$ & $-.20, .28$ \\
\hline Unsure how to prepare & $2.10(.89)$ & $-.30, .12$ \\
\hline Takes too long to prepare & $1.59(.65)$ & $-.26, .05$ \\
\hline Cost is too expensive & $2.37(.92)$ & $-.04, .40$ \\
\hline Personally don't like the taste & $1.49(.69)$ & $-.33,-.01$ \\
\hline Family does not like the taste & $1.83(.81)$ & $-.21, .13$ \\
\hline Perceived difficulty in obtaining 1 additional serving ${ }^{\text {a }}$ & $1.26(.56)$ & $-.17, .09$ \\
\hline $\begin{array}{l}\text { Note. 1 = Strongly Disagree, 2 = Disagree, 3 = Agree, 4=Strongly Agree } \\
\text { a 1 =Not at all Difficult, 2 = Somewhat Difficult, 3 = Difficult, 4= Very Difficult }\end{array}$ & \\
\hline
\end{tabular}

For barriers to fruit intake, students reported being neutral $(\mathrm{M}=2.45$ to 2.64$)$ in considering that fruit spoiled, it was difficult to obtain fruit at work or while dining out, and that fruit was too expensive. The students disagreed that they were unsure how to prepare fruit, that it took too long to prepare, that they personally and their family did not like the taste of fruit. They also indicated that it would not be difficult to increase consumption by one additional daily serving $(\mathrm{M}=1.26, \mathrm{SD}=.56)$, where, $1=$ not at all difficult, and $4=$ very difficult.
Knowledge of Fruit Intake and Relationship with Reduced Risk of Cancer Students agreed $(M=3.07)$ that health experts recommended at least two servings of fruit per day and that the fruit intake will reduce the risk of getting cancer $(\mathrm{M}=3.29, \mathrm{SD}=.69)$. The means for realizing that the foods they eat can influence risk of getting cancer, approached a neutral position $(\mathrm{M}=2.79, \mathrm{SD}=.88)$. The following percentages of students believed that fruit intake below recommended levels was associated with the following cancers: stomach $(84.8 \%)$, bladder $(77.8 \%)$, pancreatic $(73.8 \%)$, 
colorectal $(70.9 \%)$, prostate $(66.1 \%)$, breast $(65.4 \%)$, ovarian $(55.9 \%)$, and lung $(47.3 \%)$.

\section{Attitudes Predicting Fruit Intake}

Table 5 shows the results of the forward linear regression analysis. A significant regression was found $(\mathrm{F} 4,249=27.1, \mathrm{p}<.001)$, predicting $30 \%$ of the variance in fruit intake. Belief that they ate enough fruit for good health predicted $19 \%$ of the variance in fruit intake, with not being in the habit of eating fruit an additional $7 \%$, feel like they get more energy an additional $3 \%$, and fruit helps lose weight $1 \%$. The linear regression equation for the probability of fruit intake was: $\hat{Y}($ fruit intake $)=.82$ (eat fruit for good health) - .69(no habit of eating fruit) + .92 (feel energy) - .38(help lose weight) +.90 . All of the model variables were statistically significant.

Table 5

Final Forward Linear Regression Model of Attitudes Predicting Fruit Intake of Female EOPS Students

\begin{tabular}{|c|l|c|c|c|c|c|c|}
\hline Step & \multicolumn{1}{|c|}{ Predictor Variables } & B & SE & $\boldsymbol{t}$ & $\mathbf{P}$ & $\mathbf{R}$ & $\mathbf{R}^{2}$ \\
\hline 1 & Eat enough fruit for good health & .82 & .17 & 4.91 & $<.001$ & .43 & .19 \\
\hline 2 & No habit fruit intake & -.69 & .16 & -4.32 & $<.001$ & .51 & .26 \\
\hline 3 & Feel more energy with fruit intake & .92 & .23 & 4.05 & $<.001$ & .54 & .29 \\
\hline 4 & Eating fruit would help lose weight & -.38 & .19 & -2.02 & $<.05$ & .55 & .30 \\
\hline
\end{tabular}

\section{Discussion}

Overall, the questionnaire items had acceptable temporal stability and there were only small and non-significant differences across administrations. There are several potential explanations for the observed low test-retest reliability of the measures of eating fruit as an example for family and the knowledge items of recommended daily fruit intake, consumption among peers, and reduced cancer risk had poor agreement in the test-retest reliability. First, kappa statistics were used to examine the testretest reliability for all dichotomous and polychotomous variables. The kappa statistic is a conservative estimate of reliability, especially for the low prevalence measures reported here.

Second, these items may have been worded in a way that students interpreted them slightly differently thereby leading to inconsistent responses across administrations. Third, results may represent real changes in the respondents' attitudes or knowledge over the intervening period of time or as a result of taking the earlier test. Finally, issues of family, knowledge of health benefits from fruit and fruit consumption recommendations may not have been a salient topic for a large proportion of students at the Time 1 administration. Students may have become more sensitized to the topic between administrations and the results from Time 2 may be a more accurate report. The items were not discarded because they are standard questions used in nutrition assessments and may have measured real change over time.

Consistent with previous studies (California Department of Health Services, 1999), one-third of the total sample consumed fewer than the recommended minimum two servings of fruit on the previous day. This level of intake greatly increases the relative risk of multiple types of cancer. These women appear to have fruit intake levels comparable to the general population. While low quality diets are associated with low socioeconomic status (California Department of Health Services CPaNA., 1999; USDA Agricultural Research Service, 1997), these women may represent a group that is slightly different than others in their social economic level because they are trying to enhance their economic and personal situation by pursuing advanced education. They may therefore have intake behaviors resembling that of the general population. Since they are college students and therefore open to change (The National Health, 1998), these woman may be responsive to an intervention to increase fruit intake. In addition, influencing women's attitudes or behaviors that predispose them 
toward increased fruit intake would enhance the modeling behavior for their children (Cullen, et al., 2000). Approximately, 47\% believed that $40 \%$ of their peers had one serving of fruit per day. Therefore, the women may believe that the amount of fruit that they consume may be normative relative to peer intake.

Students agreed that fruit gave them energy, and factors such as thinking that fruit spoiled, that it was hard to obtain at work or while dining out, that preparation was long, that it was too expensive, and that they and their family liked the taste of fruit, were not seen as barriers to increasing fruit intake (Quan, Salomon, Nitzke $\&$ Reicks, 2000). These attitudes may make them more open to a nutrition education intervention to increase fruit intake. Contrary to previous findings, students did not indicate that fruit spoilage and expense were barriers to increased fruit consumption (Heimendinger \& Van Duyn, 1995). These findings indicate that in general, students did not perceive that there were many barriers to increasing fruit consumption and they felt that it would give them energy. Further, messages could be incorporated into media materials that would promote fruit consumption to increase energy and to be used as a type of fast food. While expense was not reported as a major barrier to fruit consumption, students have commented in informal discussions that the current price of fruit in the school cafeteria made fruit purchases less attractive. The reported price, type of fruit and presentation of the fruit (e.g. bruised) made fruit purchases in the cafeteria less likely.

Overall, students were knowledgeable about the minimum daily intake of fruit, yet a large proportion did not attain the recommended level of consumption. Previous literature (Block, et al., 1992) indicates that eating 5 or more servings of fruits and vegetables a day reduced a dozen types of cancer by half, yet one third of the total sample consumed fewer than the minimum recommended two servings of fruit on the previous day. Many students were not aware of the relationship between diet and associated cancers and diseases, an observation consistent with other studies (Nuffer, 1988; Kristal, et al., 1990). Belief in a connection between diet and cancer has been found to precede dietary changes, however knowledge of food composition did not lead to dietary change (Quan, et al., 2000). Encouraging was the fact that in the present study women reported that it would not be difficult to increase their daily consumption by one additional serving of fruit. These observations suggest that knowledge of the health benefits may be necessary but are not sufficient to positively impact fruit intake behavior. Although, in any planned intervention, the role of nutrition knowledge in food intake should not be underestimated and in recent studies has been found to explain $4 \%$ to $22 \%$ of the variation in food intake (Wardle, Parmenter \& Waller, 2000). It should be further noted that in the present study, women on average did not agree that food intake was related to cancer, but did agree that fruit would reduce their risk of cancer. So, they seem to be disposed to understanding the benefits of fruit intake on cancer risk reduction, even though they did not agree that there is a general relationship between food intake and cancer.

Beliefs that eating enough fruit for good health, being in the habit of eating fruit, feeling energy from eating fruit, and eating fruit to lose weight were significant predictors of fruit intake among EOPS college women. The results from this analysis suggests that an intervention designed to increase fruit intake may need to make women aware of the actual amount of fruit they are consuming relative to the standard recommendations. To promote fruit intake, women may be encouraged to do the behavior by distributing free samples, or encouraging fruit purchases by giving incentives for reduced cost samples at the school cafeteria or from local vendors. Women can also be given recipes, taste samples, or techniques for preparing fruit in a variety of ways. In addition, the message that fruit gives you energy may be conveyed through education and various media. Finally, it appears that women may be positively influenced to eat more fruit if they understand that fruit will help them to lose weight. Appeals to intrinsic motivations to lose weight through fruit intake may be more effective than extrinsic motivations such as using reward or perceived social pressure (Patterson, Kristal \& White, 
1996). Food intake occurs in private many times and as such this behavior is not subject to the same social scrutiny as other behaviors such as smoking.

This study had three limitations. First, the sample was restricted to EOPS women students and so it was not representative of all female students. Second, it used a cross-sectional research design that cannot be used to indicate causality. In addition, the data reported here are based on self-reports and are restricted to the limitation inherent in self-reports of dietary intake. Third, the amount of fruit consumption reported may be an overestimate of actual intake. Given these limitations, this study indicates that the EOPS women need to increase fruit consumption to achieve the minimum daily recommendations, and are at least as likely to not eat fruit as the general population. Further, given the high percentage of women who consumed fewer than the recommended minimum two servings of fruit on the previous day, the lack of perceived barriers, the willingness to increase fruit intake and the intention to enhance their personal and economic lives, this population may benefit and be receptive to an intervention to increase fruit consumption.

Future studies should examine the effects of institutional policies on the availability of fruit offered through vending machines and school cafeteria purchases and the role of nutrition knowledge in fruit intake. In addition, the efficacy of community level interventions, such as a social marketing approach to increase fruit consumption, could be determined. Data collected in this assessment can be used to establish fruit intake intervention priorities that address the identified barriers to promote increased fruit consumption.

\section{References}

American Cancer Society 1996 Advisory Committee on Diet, N., and Cancer Prevention. (1996). Guidelines on diet, nutrition, and cancer prevention: Reducing the risk of cancer with healthy food choices and physical activity. Cancer Journal for Clinicians, 46, 325-341.

Block, G., Patterson, B., \& Subar, A. (1992). Fruit, vegetables, and cancer prevention: A review of epidemiological evidence. Nutrition and Cancer, 18, 1-29.

California Cancer Facts and Figures. (2001). California cancer registry. Sacramento, CA: American Cancer Society.

California Department of Health Services CPaNA. (1999). Overall trends in healthy eating among adults 1989-1997: A call to action, part 2. Sacramento, CA: California Department of Health Services.

California Project LEAN. (2000). California Project Lean Sierra Cascade region community based social marketing plan 2000. Redding, CA: Shasta County Public Health Department.

Cullen, K. W., Baranowski, T., Rittenberry, L., Cosart, C., Owens, E., Hebert, D., \& de Moor, C. (2000). Socioenvironmental influences on children's fruit, juice and vegetable consumption as reported by parents: Reliability and validity measures. Public Health Nutrition, 3, 345-356.

DiSogra, L., Abrams, B., \& Hudes, M. (1994). Low prevalence of healthful dietary behaviors in a California agricultural county: Emphasis on white and Mexican-American adults. Journal of the American Dietetic Association, 94, 544-546.

Fleiss, J. L. (1981). Statistical methods for rates and proportions (2nd ed.). New York: John Wiley \& Sons.

Gillman, M. W., Cupples, L. A., Gagnon, D., Posner, B. M., Ellison, R. C., Castelli, W. P., \& Wolf, P. A. (1995). Protective effects of fruits and vegetables on development of stroke in men. Journal of the American Medical Association, 273, 1113-1118.

Hall, B., \& Richards, F. (1995). 1994 health data summaries for California counties. Sacramento, CA: Department of Health Services.

Health and Education Communication Consultants. (1996). Executive summary: Food on the run program. Berkeley, CA: Author. 
Heimendinger, J. \& Van Duyn, M. A. S. (1995). Dietary behavior change: The challenge of recasting the role of fruit and vegetables in the American diet. American Journal of Nutrition, 61(Suppl.), 397S-401S.

Kristal, A. R., Abrams, B. F., Thornquist, M. D., Disogra, L., Croyle, R. T., Shattuck, A. L., \& Henry, H. J. (1990). Development and validation of a food use checklist for evaluation of community nutrition interventions. American Journal of Public Health, 80, 1318-1322.

Kubik, M., Lytle, L., \& Story, M. (2001). A practical, theory-based approach to establishing school nutrition advisory councils. Journal of the American Dietetic Association, 101, 223-228.

Nuffer, S., Tucker. (1988). Public relations results - "5 a day" campaign. Sacramento, CA: California Department of Health Services and Nutrition and Cancer Prevention Program.

Patterson, R., Kristal, A. R., \& White, E. (1996). Do beliefs, knowledge, and perceived norms about diet and cancer predict dietary change? American Journal of Public Health, 86, 1394-1400.

Quan, T., Salomon, J., Nitzke, S., \& Reicks, M. (2000). Behaviors of low-income mothers related to fruit and vegetable consumption. Journal of the American Dietetic Association, 100, 567-569.

SPSS. (1999). SPSS base 10.0 applications guide. Chicago, IL: SPSS, Inc.

The Harvard report on cancer prevention. (1996). Causes of human cancer. Cancer Causes and Control, 7(1), S7-S9.

The National Health, L. A. B. I. E. P. (September 18, 1998). Executive summary of the clinical guidelines on the identification, evaluation, and treatment of overweight and obesity in adults. Archives of Internal Medicine.

U. S. Department of Health and Human Services. (2000). Healthy people 2010: Understanding and improving health (2nd ed.). Washington, DC: U. S. Government Printing Office.

USDA Agricultural Research Service. (1997). USDA 1994-96 continuing survey of food intakes by individuals and 1994-96 diet and health knowledge survey. Beltsville, MD: Beltsville Human Nutrition Research Center.

Wardle, J., Parmenter, K., \& Waller, J. (2000). Nutrition knowledge and food intake. Appetite, 34, 269275.

\section{Acknowledgments}

Funds for this study were provided by the United States Department of Agriculture (USDA) and the California Department of Health Services, California Project LEAN and the California Nutrition Network. Contract Number 00-90996. The authors would also like to acknowledge Debbie Hillyard for her assistance with data collection and entry as well as the EOPS students and staff who participated in this study.

$\underline{\text { Author Information }}$

Steven E. Shive, Ph.D., MPH, Assistant Professor

Department of Health and Community Services California

State University, Chico,

400 W. First St.

Chico, CA 95926-0505

Email: sshive@,csuchico.edu

Michelle R. Neyman, Ph.D., RD

Assistant Professor Nutrition and Food Sciences Program

Department of Biological Sciences

California State University, Chico

$400 \mathrm{~W}$. First St.

Chico, CA 95929-0002

Email: mneyman@csuchico.edu 
S. E. Shive \& M. R. Neyman / Californian Journal of Health Promotion 2003, Volume 1, Issue 1, 91-102 